\title{
Acceptability and feasibility of immediate postpartum IUCD insertion in a tertiary care centre in Central India
}

\author{
Anjali Vivek Kanhere*, Prachi Pateriya, Manisha Jain
}

Department of Obstetrics \& Gynaecology, Peoples College of Medical Sciences and Research Centre, Bhopal-462037, Madhya Pradesh, India

Received: 17 December 2014

Accepted: 11 January 2015

*Correspondence:

Dr. Anjali Vivek Kanhere,

E-mail: kanhereanju@yahoo.com

Copyright: (C) the author(s), publisher and licensee Medip Academy. This is an open-access article distributed under the terms of the Creative Commons Attribution Non-Commercial License, which permits unrestricted non-commercial use, distribution, and reproduction in any medium, provided the original work is properly cited.

\begin{abstract}
Background: This study was conducted to assess the acceptability and feasibility of immediate postpartum intrauterine contraception device insertion after vaginal deliveries in a tertiary care centre in Central India. Aims: To study acceptability, feasibility \& complications of immediate PPIUCD.

Methods: This is a prospective analytical study conducted at Department of Obstetrics and Gynecology, PCMS \& RC Bhopal. 200 eligible postpartum women were counselled for IUCD insertion. After consent, $\mathrm{Cu}-\mathrm{T} 380 \mathrm{~A}$ insertion was done. These women were also interviewed for their reasons for accepting and rejecting PPIUCD and their preference for other forms of contraception. Follow-up was done at 6 week or when they reported with any complaint. Results: Out of 200 eligible postpartum patient counselled, 72 (36\%) women underwent PPIUCD insertion which was significantly low as compared to preference to use of other methods of contraception at a later date (66\%). Acceptance of PPIUCD was higher in the age group of 21-29 years (35\%), para-1 (48\%), and educated (60\%) clients. Expulsion rate was $22 \%$. There was no case of perforation or any other major complication. 52 cases $(72 \%)$ reported for follow up. $43 \%$ of cases were comfortable with PPIUCD at 6 weeks. There was no case of perforation, PID reported in our study. Only one patient reported with intrauterine pregnancy at 6 months with IUCD in place.

Conclusions: PPIUCD was not very acceptable in our set up but it is a safe, highly effective, long acting, cost effective method of contraception with very few side effects and no major complication and contraindication. The feasibility of accepting PPIUCD insertion can increase with antenatal counselling and institutional deliveries.
\end{abstract}

Keywords: PPIUCD, Awareness, Acceptance, Expulsion

\section{INTRODUCTION}

Family planning is an essential fundamental human right for the welfare of the individual, family and society as a whole. Current population of India is $1,21,05,69,573$ (2011 census). ${ }^{1}$ India is the second largest country in the world accounting for $17.5 \%$ of world's population. With roughly 25 million births annually, India at present contribute one fifth of total world population growth more than any other country. In India, $65 \%$ of women in the first year postpartum have an unmet need for family planning. ${ }^{2}$
The common reasons for unmet need are lack of information, and fear about side effects of contraceptive method. Studies show that pregnancies taking place within 24 months of previous birth have higher risk of adverse outcome like abortion, premature labour, postpartum hemorrhage, low birth weight babies, fetal loss, and maternal death.

Women are highly motivated and receptive to accept Family Planning (FP) methods during the postpartum period. Demographic and health survey show that 40 percent of women in the first year postpartum intend to 
use a Family Planning (FP) method but are not doing so. Only $26 \%$ of women are using some method of family planning during the first year of postpartum. ${ }^{2}$

Postpartum period is one of the critical times when both woman and newborn need a special and integrated package of health services as morbidity and mortality rates are quite high and also the women are vulnerable to unintended pregnancy.

WHO medical eligibility criteria ${ }^{3}$ state that PPIUCD is safe in postpartum lactating women with advantage outweighing the disadvantage.

Advantages of immediate postpartum insertion of the IUD include client motivation, safety, convenience, assurance of no pregnancy, does not interfere with lactation, facilitates adequate birth spacing, immediately reversible and does not require repeated health care visits for contraceptive refills.

PPIUCD insertion gives these women an extra edge of leaving the hospital with contraception after institutional delivery.

\section{METHODS}

\section{Study population}

All immediate postpartum (10 min to 48 hour of delivery of placenta) women of any age group delivered vaginally at P.C.M.S. \& R.C. Bhopal.

\section{Study variables}

Acceptance or rejection of PPIUCD insertion, age, parity, family size, education, choice of other contraceptive method.

\section{Study design}

Prospective longitudinal study.

\section{Study time}

01 January 2012 - 30 August 2013

\section{Inclusion criteria}

Women delivered by normal vaginal delivery at P.C.M.S. \& R.C.

\section{Exclusion criteria}

Known distorted uterine cavity, acute purulent discharge, Malignant or benign trophoblastic diseases, Chorioamnionitis, Prolonged rupture of membrane. Unresolved postpartum hemorrhage, Tear during delivery.

\section{Research instrument}

$\mathrm{Cu}-\mathrm{T}$ 380A

\section{Counselling of the patients}

During ANC visits, during admission if not booked case. During early labour, on $1^{\text {st }}$ post-partum day. Women who accepted PPIUCD were interviewed for their cause of acceptance and women who were reluctant for PPIUCD were interviewed for their reasons for rejection and their choice for other method of contraception.

The proforma was prepared in form of questionnaire the information for acceptability and rejection were analyzed by the same.

\section{Procedure}

After the active management of $3^{\text {rd }}$ stage of labour, bimanual examination was performed. Written consent was taken from the women. All the required things were arranged in a tray. Cervix was visualized using speculum and retractor. IUCD pack was aseptically opened. Copper- $T$ was held in right hand and slowly inserted through the cervix in to the lower uterine cavity, left hand was placed on top of a sterile sheet over the abdomen, Copper-T was slowly moved upward till the fundus of uterus. The hand over the fundus and copper-T are approximated and then IUCD was left at the fundus and the hand was slowly moved out, while stabilizing the uterus with outside hand. Strings were cut to the level of the cervix.

\section{Follow up}

Follow up was scheduled at 6 weeks or with any other complaint.

\section{RESULTS}

200 eligible postpartum patients were counselled for PPIUCD insertion during their antenatal visits. Out of this 72 patient accepted PPIUCD insertion with proper consent. Acceptance rate was 36\% (Table 1).

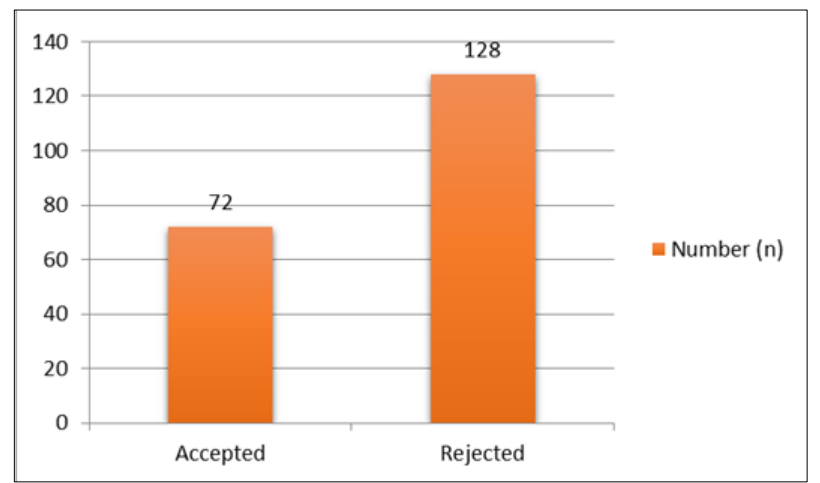

Figure 1: Acceptance vs. rejection of PPIUCD. 
Table 1: Acceptance vs. rejection of PPIUCD.

\begin{tabular}{|lll|}
\hline & $\mathrm{N}=200$ & $\%$ \\
\hline Accepted & 72 & 36 \\
\hline Rejected & 128 & 64 \\
\hline
\end{tabular}

Majority of patient counselled were between age group of 20-29 years $177(88.5 \%), 62(35 \%)$ accepted PPIUCD insertion. Above 30 years. $60 \%$ refused IUCD insertion because they were inclined for accepting permanent method of contraception (Table 2).

Table 2: Age variables for different groups.

\begin{tabular}{|llll|}
\hline Age & Accepted & Declined & Total \\
\hline$<19$ years & $1(100 \%)$ & 0 & $1(0.5 \%)$ \\
\hline $20-29$ years & $62(35 \%)$ & $115(65 \%)$ & $177(88.5 \%)$ \\
\hline $30-39$ years & $9(40 \%)$ & $13(60 \%)$ & $22(11 \%)$ \\
\hline Total & 72 & 128 & 200 \\
\hline
\end{tabular}

Chi square value $=2.08 ; \mathrm{P}$ value $=0.35$

$87 \%$ were literate though acceptance rate for PPIUCD was $37 \%$. $7 \%$ were educated up to graduate level, equal number $50 \%$ was there in acceptance \& rejection group maximum patient $(38 \%)$ were educated up to $12^{\text {th }}$ grade $43 \%$ accepted PPIUCD (Table 3 ).

Table 3: Acceptance and rejection according to education.

\begin{tabular}{|lllll|}
\hline Education & Acceptance & Rejection & Total & $\%$ \\
\hline Illiterate & $7(27 \%)$ & $19(73 \%)$ & $26(13 \%)$ & 13 \\
\hline $5^{\text {th }}$ grade & $12(34 \%)$ & $23(66 \%)$ & $35(17 \%)$ & 18 \\
\hline $5^{\text {th }}-8^{\text {th }}$ grade & $13(27 \%)$ & $36(73 \%)$ & $49(25 \%)$ & 25 \\
\hline $8^{\text {th }}-12^{\text {th }}$ grade & $33(43 \%)$ & $43(57 \%)$ & $76(38 \%)$ & 38 \\
\hline graduate & $7(50 \%)$ & $7(50 \%)$ & $14(7 \%)$ & 7 \\
\hline Total & 72 & 128 & 200 & 100 \\
\hline
\end{tabular}

Chi square test $=5.89 ; \mathrm{P}$ value $=0.2$

Most of the patients were para-1 (48\%). Maximum number of patient interviewed were primi gravida $44 \%$ $(\mathrm{N}=98)$, out of them $48 \%$ accepted PPIUCD. Only $27 \%$ of grand multipara accepted PPIUCD (Table 4). In my study acceptance of the PPIUCD was lower among grand multiparous $(27 \%)$ compared to primiparous $(48 \%)$ which is statistically significant.

Table 4: Acceptance and rejection according to parity.

\begin{tabular}{|lll|l|}
\hline Parity & $\begin{array}{l}\text { Accepted } \\
\mathbf{N}=72\end{array}$ & $\begin{array}{l}\text { Declined } \\
\mathbf{N}=128\end{array}$ & $\begin{array}{l}\text { Total } \\
\mathbf{N}=200\end{array}$ \\
\hline 1 & $47(48 \%)$ & $51(52 \%)$ & $98(44 \%)$ \\
\hline 2 & $13(22 \%)$ & $45(78 \%)$ & $58(29 \%)$ \\
\hline$>3$ & $12(27 \%)$ & $32(73 \%)$ & $44(27 \%)$ \\
\hline
\end{tabular}

Chi square value $=12.2 ; \mathrm{P}$ value $=0.002$
Table 5 shows distribution of subjects according to antenatal care, $111(56 \%)$ were booked antenatal out of which $44 \%$ of booked patients accepted PPIUCD and only $25 \%$ unbooked patient accepted PPIUCD. This was of significant association $(\mathrm{P}=0.007)$.

Table 5: Distribution of subjects according to antenatal care.

\begin{tabular}{|llll|}
\multicolumn{3}{c}{ Accepted } & Rejected \\
\hline Booked & $49(44 \%)$ & $62(56 \%)$ & $111(56 \%)$ \\
\hline Unbooked & $23(25 \%)$ & $66(75)$ & $89(46 \%)$ \\
\hline Total & 72 & 128 & 200 \\
\hline
\end{tabular}

Chi square $=7.18 ; \mathrm{P}$ value $=0.007$

Table 6 shows the reasons of acceptance of PPIUCD. $28 \%$ as it was long acting followed by less follow up $20 \%$ and reversibility $17 \%$.

Table 6: Reasons for Acceptance of PPIUCD among parturient whom IUCD was inserted.

\begin{tabular}{|ll|}
\hline Reasons & N=72 \\
\hline Long acting & $20(28 \%)$ \\
\hline Fewer follow up visit & $15(20 \%)$ \\
\hline Reversible & $12(17 \%)$ \\
\hline Safe & $7(10 \%)$ \\
\hline Non hormonal & $7(10 \%)$ \\
\hline Less attention for the use & $8(11 \%)$ \\
\hline No interference with breast feeding & $3(4 \%)$ \\
\hline
\end{tabular}

Table 7 shows reasons of declining usage of PPIUCD. $32 \%$ were inclined to use other form of contraception. $20 \%$ wanted to adopt permanent method and $10 \%$ had no reason for declining. $47 \%$ preferred male condom and declined PPIUCD insertion (Table 8).

Table 9 shows follow up by $72 \%, 43 \%$ had no complaints. Expulsion was observed in $22 \%$. Partial expulsion was in $12 \%$.

One patient reported with intrauterine pregnancy with IUCD in place. There was no report of uterine perforation or PID (Table 10).

Table 7: Reasons for declining PPIUCD.

\begin{tabular}{|ll|}
\hline Reasons & $\mathbf{N}=128$ \\
\hline $\begin{array}{l}\text { Inclination for other forms of } \\
\text { contraception }\end{array}$ & $41(32 \%)$ \\
\hline Permanent method & $25(20 \%)$ \\
\hline No contraception & $18(14 \%)$ \\
\hline Menstrual irregularities, pain & $16(13 \%)$ \\
\hline Fear of future fertility & $6(5 \%)$ \\
\hline Family pressure & $12(9 \%)$ \\
\hline No reason & $10(10 \%)$ \\
\hline
\end{tabular}


Table 8: Preferences for other forms of contraception, among those declining PPIUCD.

\begin{tabular}{|ll|}
\hline Method & Total \\
\hline Male condom & $40(47 \%)$ \\
\hline DMPA & $4(5 \%)$ \\
\hline Interval IUCD & $11(13 \%)$ \\
\hline Pills & $6(7 \%)$ \\
\hline Abstinence & $8(9 \%)$ \\
\hline Natural method & $16(19 \%)$ \\
\hline Total & $85(100 \%)$ \\
\hline
\end{tabular}

Table 9: Follow-up.

\begin{tabular}{|ll|}
\hline Follow-up & $\mathrm{N}=72$ \\
\hline Yes & $52(72 \%)$ \\
\hline No & $20(28 \%)$ \\
\hline
\end{tabular}

Table 10: Presentation at 6 weeks.

\begin{tabular}{|ll|}
\hline Presentation & Total N=54 \\
\hline No complaints & $23(43 \%)$ \\
\hline Expulsion & $13(22 \%)$ \\
\hline At cervical canal & $7(12 \%)$ \\
\hline Pain & $5(8 \%)$ \\
\hline Menstrual irregularities & $4(6 \%)$ \\
\hline Missing thread & $2(3 \%)$ \\
\hline Perforation & $0(0 \%)$ \\
\hline
\end{tabular}

\section{DISCUSSION}

Looking into the exploding population of India, population control and stabilization is the demand of the nation for its socioeconomic development and welfare of country. Although the available contraceptive methods are many, need of a single efficacious, feasible, and costeffective method is desirable especially in low resource country like, India.

The present study was conducted to assess the acceptability, feasibility and complications of IUCD insertion in immediate postpartum period of women delivering in our setup. This study included 200 postpartum subjects. All participants after informed consent were included in the study and divided into two groups based on the acceptance or refusal for IUCD insertion.

In present study, $72(36 \%)$ women were willing for PPIUCD insertion. 128 (64\%) women refused PPIUCD insertion.

A study done by Mohamed et al. ${ }^{4}$ shows that making contraceptive methods easy and convenient for women makes a big difference in ultimate acceptance. In their study, 1024 women were counselled for immediate postpartum insertion of IUCD. Of those who agreed for immediate insertion, $71.2 \%$ had the IUCD inserted. Compared to this study acceptance rate in our study is low, possible reasons could be lack of awareness, low education, family pressure and various misconceptions for IUCD insertion.

In our study it was observed that PPIUCD acceptance was more with booked antenatal patient. This was concluded in the study done by Mohamed et al. ${ }^{4}$ which suggests integration of family planning with maternal and child-care services in order to effectively promote the use of contraceptive devices in these women who otherwise would not seek the use of such a device.

In this study maximum patient (38\%) were educated up to $12^{\text {th }}$ standard \& $43 \%$ of them accepted PPIUCD. $13 \%$ were illiterate and $73 \%$ of them rejected the use of PPIUCD from this group which is not significant. Women who were graduate, acceptance and rejection rate was $50 \%$. Education has a positive effect on acceptance of PPIUCD insertion but various misconceptions overpowered the acceptance. Choudhary et al. found secondary and higher education influenced contraceptive use. ${ }^{5}$ Ullah and Chakraborty showed women's education as the most important determinant of contraceptive use. ${ }^{6}$

In our study acceptance of the PPIUCD was lower among grand multiparous (27\%) compared to primiparous (48\%) which is statistically significant. Study done by Safwat et al. $^{7}$ in Egypt where $30 \%$ of primiparous accepted the use of PPIUCD compared to $15 \%$ of multipara. In our study majority of multipara patient were interested in permanent method of contraception \& inclination of primiparous remains towards spacing methods. Advantages of immediate post-partum insertion include high motivation, assurance that the woman is not pregnant, and convenience Grimes D. ${ }^{8}$

In our study, 128 cases who refused for post-partum IUCD insertion were interviewed for cause of refusal and also their choice for other contraception. 32\% were interested in using other type of contraception. This was consistent with the study of Rajni Gautam, K. N. Arya ${ }^{9}$ However $20 \%$ were interested in permanent method of contraception at a later date. $14 \%$ did not accept any contraception. $13 \%$ had fear of menstrual problems like irregularities and pain. $5 \%$ had fear of future infertility. 9\% patients refused accepting PPIUCD insertion under family pressure (the deciding factors were husband and mother in law) and $8 \%$ could not specify the reason. Priya et al., ${ }^{10}$ they explored the reasons behind low acceptance of PPIUCD. They found most common reason for low acceptance of PPIUCD is lack of involvement of husband.

In our study 52 cases (72\%) reported for follow up. $43 \%$ of cases were comfortable with PPIUCD, with no complaints. $57 \%$ had few problems with the IUCD use . $22 \%$ presented with expelled IUCD, seven (12\%) presented with IUCD at Cervical canal among them reintroduction was done in 5 cases. Rest 2 cases were not willing for reintroduction Tatum $\mathrm{HJ}$ et al. ${ }^{11}$ found that the gross cumulative expulsion rate in their study was 
16.2\% ${ }^{14}$ According to Bhalerao et al. ${ }^{12}$ the expulsion rate was $16.4 \%$. The high incidence was considered due to atrophic or bulky uteri present in some. Post insertion pain was there in $8 \%$. Irregular bleeding was present in $6 \%$ patient. There was no case of perforation, PID, endometritis reported in our study. This was consistent with the study of Katheit G. ${ }^{13}$ As per Kapp N, Curtis $\mathrm{KM}^{14}$ there was no increase in risk of complications with PPIUCD insertion.

One women presented after 6 month of PPIUCD insertion with early intrauterine gestational sac, pregnancy was terminated because of failure of contraceptive. Which compares favorably with the estimated failure rates for IUCDs of 0.1 to $0.8 \%$, According to UN 1997. ${ }^{15} 13 \mathrm{CuT}$ 380 A confers contraceptive protection similar to that achieved with tubal Sterilization. ${ }^{16}$

\section{Limitations}

This study was conducted in a tertiary centre therefore the findings may not adequately reflect the entire population. Lost to follow up as observed in the study was a limitation of the study. This made it difficult to draw a clear conclusion as what happened to those who did not complete their follow up schedule.

\section{CONCLUSIONS}

Immediate postpartum IUCD insertion is safe, effective, low cost, long acting spacing method. It is concluded from our study that it is a feasible and acceptable method of contraception. The feasibility of accepting PPIUCD insertion can increase with antenatal counselling and institutional deliveries. Acceptance is high in primiparous patients where spacing method of contraception is of choice.

Although PPIUCD has high expulsion rate, but looking into current increasing population of India, it is better to give this contraceptive option than leaving a postpartum women on risk of another pregnancy with in short interval.

\section{ACKNOWLEDGEMENTS}

The authors would like to thank the institute and the department for their support. We would also like to thank the patients for their participation and cooperation.

Funding: No funding sources

Conflict of interest: None declared

Ethical approval: The study was approved by the institutional ethics committee

\section{REFERENCES}

1. India at Glance - Population census 2011. Census organization of India, 2011. Available at: http://censusindia.gov.in/2011-prov-

results/indiaatglance.html. Accessed 1 January 2014.

2. John A. Ross, William L. Winfrey contraceptive use, intention to use and unmet need during the extended postpartum period international family planning perspectives. Int Fam Plann Persp. 2001;27(1):20-7s.

3. World Health Organization: Medical eligibility criteria for contraceptive use. In: WHO, eds. WHO Book. 4th ed. Geneva: World Health Organization; 2010.

4. Mohamed SA, Kamelss MA, Shaaban OM, Salem HT. Acceptability for the use of postpartum intrauterine contraceptive devices: Assiut experience. Med Princ Pract. 2003;12:170-5.

5. Choudhary RH. The influence of female education, labour force participation \& age at marriage on fertility behavior in Bangladesh. Soc Biol. 1984;31(1-2):59-74,

6. Ullah MS, Chakraborty N. The use of modern \& traditional methods of fertility control in Bangladesh: a multivariate analysis. Contraception. 1994;50(4):363-72.

7. Safwat A, Mohamed Momen A, Kamel Omar M, Shaaban HT, Salem. Acceptability for the use of postpartum intrauterine contraceptive devices: Assuit experience. Med Principl Pract. 2003;12:170-5.

8. Grimes D, Schulz K, Van Vliet H, Stanwood N. Immediate post-partum insertion of intrauterine devices. Cochrane Database Syst Rev. 2010;(5):CD003036.

9. Rajni Gautam, K. N. Arya, S. Kharakwal, Sudhir Singh, Monika Trivedi. Overview of immediate PPIUCD application in Bundelkhand region". J Evol Med Dent Sci. 2014 Aug;3(36):9518-26.

10. Priya Jha. Compendium of sessions addressing south Asian health at the 2012 APHA meeting. In: Priya Jha, eds. SAPHA Compendium. India: Compiled by the South Asian Public Health Association (SAPHA); 2012: 8-72.

11. Tatum HJ, Beltran RS, Ramos R, Van Kets H, Sivin I, Schmidt FH. Immediate post placental insertion of GYNE-T380 and GYNE-T380 postpartum intrauterine contraceptive device. Am J Obstet Gynaecol 1996 Nov;175(5)1231-5.

12. Bhalerao AR, Purandare MC. Post-puerperal $\mathrm{Cu}-\mathrm{T}$ insertion: a prospective study. J Postgrad Med. 1989;35:70.

13. Katheit G, Agarwal J. Evaluation of post-placental intrauterine device (PPIUCD) in terms of awareness, acceptance, and expulsion in a tertiary care centre. Int J Reprod Contracept Obstet Gynaecol. 2013;2:539-43.

14. Kapp N, Curtis KM. Intrauterine device insertion during the postpartum period: a systematic review. Contraception. 2009 Oct;80(4):327-36.

15. United Nations Population Information Network (POPIN), 3. UN population division, department of economic and social affairs with support from UN population fund. IUD insertion timing vital in 
postpartum use. Network intrauterine devices. Family health international. Winter. 1996;16(2):1-3.

16. Kaneshiro B, Aeby T. Long-term safety, efficacy, and patient acceptability of the intrauterine Copper T-380A contraceptive device. Int J Women's Health. 2010 Aug;2:211-20.
DOI: $10.5455 / 2320-1770 . i j r \operatorname{cog} 20150232$

Cite this article as: Kanhere AV, Pateriya P, Jain M. Acceptability and feasibility of immediate postpartum IUCD insertion in a tertiary care centre in Central India. Int J Reprod Contracept Obstet Gynecol 2015;4:179-84. 